\title{
Implementing Problem-Based Learning in an Undergraduate Psychology Course
}

\author{
H. Russell Searight, PhD \\ Associate Professor, Department of Psychology \\ Lake Superior State University \\ Barbara K. Searight, PhD \\ Adjunct Professor, Department of Communication \\ Lake Superior State University
}

Problem-based learning (PBL) is a small-group pedagogical technique widely used in fields such as business, medicine, engineering, and architecture. In PBL, pre-written cases are used to teach core course content. PBL advocates state that course material is more likely to be retained and applied when presented as cases reflecting "real life" applications of class material. However, rather than traditional lecture-discussion, PBL encourages student autonomy in analyzing cases, with the instructor serving initially as a structuring facilitator before gradually becoming less active as students take more responsibility for their learning. As students proceed through each case, they address four dimensions: What they know, what they want to know, possible causal hypotheses, and questions that can be answered through library research. The $P B L$ cases referred to herein were developed and employed for an undergraduate psychology course, "Psychology of the Exceptional Child."

Students completing this course included psychology, special education, and human service majors and have positively evaluated this technique as a teaching tool.

\section{Introduction to Problem-Based Learning}

Problem-based learning (PBL) is a small-group educational technique in which students apply course material to practical problems or clinical cases. Cases may be taken or adapted from published sources, or the instructor may develop vignettes specifically for a particular course. The cases focus on core course content and include sufficient ambiguity to reflect realistic clinical or applied practice.

PBL assumes that students are more likely to acquire and retain information when they are challenged to apply course content to applied dilemmas (Barrows, 1996). In addition, PBL attempts to simulate the types

\section{Problem-based learning proponents emphasize that course content is more likely to be implemented and retained when it is embedded in "real world" situations.} of reasoning and critical thinking characteristic of practitioners and investigators in the discipline of interest. Finally, since PBL is typically conducted in small groups with a faculty facilitator, students are challenged not only to work cooperatively but also to reflect on their own and their fellow students' problem-solving styles.

\section{Background of Problem-Based Learning (PBL)}

PBL was originally developed for medical education and its origins are often traced back to McMaster University in Hamilton, Ontario, where PBL was implemented approximately 30 years ago. This approach has since been applied to disciplines such as public policy, pharmacy, and special education, as well as psychology. PBL proponents emphasize that course content is more likely to be implemented and retained when it is embedded in "real world" situations (Dolmans \& Schmidt, 1996). Many medical schools have implemented PBL as the principal approach to instruction in courses such as genetics, psychiatry, and family medicine. 


\section{Relevant Research on PBL}

Research on PBL has focused on two issues: Educational processes and knowledge outcomes. Research conducted in medical settings suggests that there are four essential characteristics of effective PBL facilitators: Collaboration, directing, integration, and interaction/accountability. Collaboration consists of stimulating brainstorming by asking questions and follow-up clarifications. Directing the learning process includes helping students generate learning issues and indirectly drawing attention to students' gaps in knowledge. Stimulating integration of knowledge encourages students to examine their information in the context of previous cases or course material. Finally, stimulating interaction and individual accountability encourage students to make an inventory of learning resources (DeGrave, Dolmans, \& van derVleuten, 1999).

Results of research on student learning have been mixed. An early review of $\mathrm{PBL}$ in medical education suggested that when compared with a traditional curriculum, PBL was associated with greater long-term retention of content, better self directed learning skills and improved critical thinking skills (Norman \& Schmidt, 1992). In examining PBL's effects in a graduate clinical psychology training program, interactive skills such as working within a team, responsiveness to supervision and collective efficacy appeared to improve over time (Stedman, Wood, Curle, \& Haslam, 2005; Wood, 2004).

\section{Construction of PBL Cases}

Cases are selected or written to address specific course objectives. In this respect, PBL, at least conceptually, differs little from objective-driven guides to curriculum development. For example, if schizophrenia is a topic to be addressed in an abnormal psychology class, the case would include common symptoms of the condition as well as demographic features associated with schizophrenia. The patient's behavior may include features of schizophrenia subtypes (e.g., paranoid, undifferentiated), as well as both positive and negative symptoms. Historical and family information about the patient may suggest a genetic diathesis possibly exacerbated by a domestic environment high in expressed emotion. The case study narratives should include enough ambiguity to reflect realistic diagnostic and etiological dilemmas, while also encouraging critical analytic reasoning. Additionally, by having the case appear on sequential pages, the format reflects clinical reasoning and problem-solving: As new information is compared and/or integrated with previous clinical data, new hypotheses are developed.

While there are a growing number of published PBL cases written by professionals in areas such as medicine, psychology, counseling, and social work, instructors may prefer to write their own cases. In this way, the cases can be more directly tailored to specific course curricula. Additionally, many departments now have specific objectives attached to their core courses. This is particularly true for disciplines such as education and nursing in which there are state guidelines for course content. It is helpful to frequently refer to these objectives as the written case is developed. In this process, having a clear set of objectives will help maintain focus while adding realistic details and sufficient ambiguity to engage student interest. 


\section{A Step-wise Approach to Developing PBL Cases}

PBL cases can be systematically developed through the following steps:

1. List the specific educational objectives as criteria that the case should illustrate.

2. Write the case in narrative form, using the criteria as a rough checklist.

3. If there are multiple objectives that build upon one another, develop a list that organizes the objectives into those that should be addressed early in the course of the case and those addressed as the case later unfolds.

4. In writing the case, include a specific and limited number of pieces of information -- typically no more than three points -- in each paragraph. This organizational plan facilitates discussion of the impact that specific new content has on students' evolving understanding of the case.

5. Paragraphs should be brief (three sentences) and each page should have no more than two paragraphs.

6. Cases should include demographic information as well as content reflecting cultural and gender diversity issues. For example, one of the cases used early in the semester in an abnormal psychology class involves an adolescent female who is having a lesbian relationship. She is brought to the office by her parent with the request that the counselor change the young woman's sexual orientation.

7. Each of the cases should include "clues" in the form of pieces of information that raise hypotheses, particularly in the context of other facts about the case. For example, a reference to facial features such as a smooth philtrum and a thin upper lip might mean little outside the context of accompanying details-for example, previously presented evidence of cognitive deficits. Taken together, these details can suggest the possibility of fetal alcohol syndrome.

8. Typically, the cases should place the students/readers in a particular role. Roles may include mental health counselor, special education teacher, or preschool director who needs to make a specific decision about the case. These roles set the information in an applied context and also encourage students to consider how different professionals might prioritize information and approach problems.

\section{Four-Part Category System for Organizing PBL Cases}

In order to provide some structure for the case discussion, as well as to provide some specific parameters for critical analysis, the small group discussion should be organized around four categories:

1. What do we know? -- available facts about the case;

2. What we would like to know? -- what additional information would help answer important open questions about the case;

3. Hypothetical causal relationships --- a form of "mind mapping." This is a visual technique of developing a schematic diagram of key concepts in an area of study. One or a limited number of central characteristics are the nexus of the diagram with related material branching off of this center (Budd, 2004). For example, the concept of schizophrenia may have central lines emanating from it indicating biological and psychosocial factors. The biological branch might have "genetics" as a central "trunk" with specific brain abnormalities (e.g., enlarged ventricles) and neurotransmitters (e.g., dopamine) as branches.

4. Learning issues -- questions arising during the discussion that can be answered by focused library research. 
These dimensions are listed at the top of four blank columns that are filled in during the course of the discussion with relevant information. Ideally, a student-participant rotates through the role of "scribe" and writes material on an easel, chalkboard, or whiteboard throughout the session.

\section{Initial PBL Session}

The first session with a new group of students should begin with an orientation to PBL. Since some students may have been exposed to PBL in previous undergraduate classes, it is useful to ask for brief accounts of previous experiences so that similarities and differences between the current use of PBL and any previous courses may be highlighted. Students' opinions about PBL may also be elicited.

The rationale for PBL should be explained. The principle of learning through real-world cases is generally well-received by students. The facilitator can enhance students' self-efficacy by emphasizing students' roles as self-directed learners and establishing a "brainstorming" norm. By writing students' contributions on the four column chart, the facilitator underscores the value of students' ideas. The four categories that organize the discussion should be briefly described next. Since PBL categories, in particular the last category, involve activity outside the classroom, some time should be devoted to explaining learning issues. Specifically, questions will arise for which a ready answer is unavailable without library research. In the latter part of each session, students will select (a) learning issue(s) to investigate and present at the next meeting. It may be necessary for the instructor to present basic ground rules for sources (for instance, peer-

The facilitator can enhance students' self-efficacy by emphasizing students' roles as self-directed learners and establishing a "brainstorming" norm. reviewed articles and or textbooks as sources; no Wikipedia selections) and presentations (for instance, a five minute presentation accompanied by a brief handout; brief description of sources; and evaluation of sources' credibility) of learning issues for the PBL group.

Students should take turns reading segments. All students as well as the facilitator have a copy of the case and follow along while the material is being read. The instructor should have a preset place in the text at which each student should stop reading and discussion should ensue. These stopping points are usually based upon the number and/or significance of new pieces of information about the case. After completion of the segment, the group should organize the new data and accompanying hypotheses and questions into the four categories.

To encourage discussion and establish a norm of group responsibility, the facilitator, in early sessions may need to "prime the pump." In particular, students in these early sessions may underestimate the significance of available information such as age and gender and how it may impact the likelihood of various hypotheses. For example, males are 4 to 8 times more likely than females to be diagnosed with attention deficit hyperactivity disorder (AD/HD) (Searight, Gafford, \& Evans, 2008). The facilitator may need to ask meta-cognitive questions focusing on the types of additional information that would be helpful to have and/or hypotheses that could be generated at a particular stage of the case. After several contributions of framing questions and information in the context of the four-part framework, students will typically take over these tasks and the facilitator can begin a process of fading to a less central role.

Learning issues should be the focus of the meeting's final 10-15 minutes. The list of topics should be presented on the board and students invited to select a topic to investigate and report on at the next meeting. If a large number of learning issues are generated, students may be invited to collapse or condense topics. As noted above, students unfamiliar with PBL may benefit from guidance about how to investigate and present their topic. In some groups, the facilitator may take a learning issue to model in a presentation to the group, demonstrating proper 
citation of sources. Finally, students should be asked to consider how the newlyobtained information would bear on the case at hand.

\section{Second and Subsequent PBL Sessions}

Ideally, the chart from session 1 will be available at subsequent sessions. If the chart is not available, the instructor should maintain a copy including learning issue assignments.

The subsequent session typically opens with students individually presenting their learning issues. There are several process dimensions that the facilitator should monitor during these presentations. Setting a norm for group interaction around learning issues is important. The rest of the group should be encouraged to give feedback and ask questions of the presenter. Particularly if students are reserved, the facilitator may initially model how to question and provide respectful feedback to the presenter.

Time is often an issue. The presentations and subsequent discussion will often take more than the three to five minutes allotted for each presentation. The facilitator should attempt to structure the discussion but avoid doing so in a way that cuts off the presenter or group discussion. The facilitator will often need to decide which is more worthwhile--discussing learning issues or covering more case material. Providing students with feedback about the quality of their learning issue presentations and the appropriateness of their background research becomes a delicate issue. Students may not have any framework for researching and presenting learning issues prior to the PBL experience. If several students' presentations are less than optimal, the facilitator could have a relevant learning issue presentation pre-prepared and present it. If evaluation anxiety within the group is at manageable levels, the group can be invited to discuss each of the presentations and their informational value. Finally, an outline describing how to investigate and present learning issues can be developed by the facilitator and made available to the group. Again, a balance between facilitator-imposed structure and group initiative is desirable.

Students often have to be prompted as a group to apply the new information from the learning issues to the case. Several questions are useful for promoting group reflection such as: "Does this new information make a difference in your understanding of the case?" and "Does this new information lead you to a next step?"

After all learning issues have been presented, the session should follow in the same vein as the previous session. After the learning issues have been discussed and integrated with the available information about the case, the group returns to the point in the case narrative at which they previously left off.

\section{Interpersonal Aspects of PBL}

Periodically, it may be helpful for the group to examine its own process, including the role of the facilitator. This reflection can be prompted by asking group members to consider their own learning processes and outcomes with questions such as, "How has this process been for the group?" and "Do you feel that your learning goals are being met?" These inquiries serve several functions. First, they emphasize the responsibility of group members for their own learning. Second, if asked in early meetings, the facilitator can make any necessary adjustments such as the difficulty of the cases. Finally, if the format is confusing to students, the facilitator can further explain the rationale for PBL and provide additional structure during class discussions and student presentations of learning issue research.

In forming PBL groups, an optimal size is approximately five to eight students. Barrows (1985) suggested a group size of five during the preclinical medical school years. Larger groups have been conducted when necessary because of a limited number of faculty facilitators. In similar situations, it may be useful to consider dividing the larger number of students into two smaller groups with a 
"roving" facilitator dividing time between the two groups. This approach will be more workable if students have had previous PBL exposure and/or are more selfdirected with good leadership skills. Smaller groups can be very productive if all students are active.

Group composition varies. Students may be at the same year level in their respective disciplines or at consecutive year levels (e.g., first and second-year students combined). A greater disparity in educational level could contribute to more advanced group members having disproportionate input and younger students being intimidated.

\section{The Facilitator's Role}

The faculty facilitator sets the tone and plays a major role in setting group norms conducive to learning. In early work on PBL, the role of the facilitator was primarily to ask meta-cognitive questions such as "Why?," "How do we know that?," and "Is there anything else?". The facilitator was not advised to provide information or to directly evaluate student contributions (Savery \& Duffy, 1995). However, it is important for the facilitator to model reasoning with questions such as "Do you know what that means?" and "What are the implications of that?". By modeling this metacognitive approach, it is assumed that students will soon begin critically examining information in the same way (Barrows, 1985).

By having material up on a whiteboard or chalkboard, the facilitator can gently direct students to the case if the discussion becomes tangential. Again, over time, students will do this re-orienting, themselves. Also, by raising group process questions like those noted above, the facilitator reiterates that it is the students' responsibility to use the experience for their own learning.

Many PBL trainers have argued that it is not necessary for the facilitator to have content knowledge of the discipline for which the cases were developed. In theory, someone knowledgeable about PBL facilitation, with no academic background in medicine, could serve

\section{Well-developed group} process skills and metacognitive questioning are seen as more important than the facilitator's content knowledge.

as an effective facilitator for a PBL group on obstetrics. Well-developed group process skills and metacognitive questioning are seen as far more important than the facilitator's content knowledge. However, it is important to note that basic knowledge in the field is helpful for formulating appropriate questions as well as for appreciating learning issues.

\section{Evaluation of PBL in an Undergraduate Psychology Class}

Originally trained in PBL in a medical school setting, the first author has been applying the technique in an undergraduate course "Psychology of the Exceptional Child and Adolescent," writing the PBL cases specifically for this class. Cases include scenarios as varied as an adolescent forced by her family to see a counselor because of her sexual orientation; a four-year-old boy presenting for admission to a preschool with a history of disruptive behavior and probable fetal alcohol syndrome; a 12-year-old with evidence of a mood disorder; and a bilingual child with possible evidence of a learning disability. To date, PBL has been used with two sections of students-one section with nine students and the other section (a summer course) with three students. Students represented an array of majors including psychology, human services, early childhood education, exercise science, and special education. While this application has not been evaluated quantitatively, end-of-the semester course evaluations indicated that students found the cases to be particularly helpful for learning common mental health conditions. Representative qualitative comments included:

- "Case studies are brilliant" 
- $\quad$ "The case studies really helped the material soak in and going through them was a great way to memorize symptoms of the disorders as well as diagnosis/classification."

- $\quad$ "Loved the case studies; it makes it easy to apply what you've learned to real-life situations."

Informal observation suggested that students were more engaged and demonstrated more active critical thinking in PBL sessions than in traditional lecture-discussion. For example, without the facilitator's prompting, students became fairly adept at engaging in differential diagnosis using behavioral descriptions, history, and demographic information. In addition, as the sessions progressed, students exhibited improved skills in using available information to generate hypotheses and using subsequently-presented information to refute or support these tentative models.

Further evaluations should include both qualitative and quantitative approaches. A quantitative measure which has been used in somewhat similar settings to assess PBL's impact is the California Critical Thinking Disposition Inventory (Facione, Facione, \& Sanchez, 1994). This instrument could be used as a pre and post-test measure administered at the beginning and end of the semester. Examination of qualitative and quantitative information could be obtained through audio and/or video taping PBL sessions. Video taping has been suggested by Woods (2004) and would provide useful group process information as well as quantitative data such as the average participation by group members and number of hypotheses generated.

\section{References}

Barrows, H.S. (1985). How to design a problem-based curriculum for the pre-clinical years. Springfield, IL: Charles Thomas Publishers.

Barrows, H.S. (1996). Problem-based learning in medicine and beyond: A brief overview. New Directions for Teaching and Learning, 68, 3-12.

Budd, J.W. (2004). Mind maps as classroom exercises. The Journal of Economic Education, 35, 35-41.

Facione, N.C., Facione, P.A. \& Sanchez, C.A. (1994). Critical thinking disposition as a measure of competent clinical judgment: The development of the California Critical Thinking Disposition Inventory. Journal of Nursing Education, 33, 345-350.

Norman, G.R. \& Schmidt, H.G. (1992). The psychological basis of problem-based learning: A review of the evidence. Academic Medicine, 67, 557-565.
Savery, J.R. \& Duffy, T.M. (1995). Problem-based learning: An instructional model and its constructivist framework. Educational Technology, 35, 31-38.

Searight, H.R., Gafford, J., \& Evans, S. (2008). Attention

Deficit/Hyperactivity Disorder. In M. Mengel \& P. Schwiebert (Eds.). Ambulatory Care and Prevention (Fifth Edition). New York: McGrawHill.

Stedman, J., Wood, J., Curle, C. \& Haslam, C. (2005). Development of $\mathrm{PBL}$ in the training of clinical psychologists. Psychology Learning and Teaching, 5, 52-60.

Tiwari, A. ,Lai, P. So, M., Yuen, K. (2006). A comparison of the effects of problem-based learning and lecturing on the development of students'critical thinking. Medical Education, 40, 547-554.

Wood, J. (2004). Report of PBL Implementation in D. Clin. Psych. Programme. Exeter, School of Psychology: University of Exeter. 


\section{Note}

An earlier version of this paper was presented at the National Institute on the Teaching of Psychology, St. Petersburgh, FL, January 4, 2009.

Russell Searight received his Ph.D. in clinical psychology from Saint Louis University in 1984. In 2003, he received his master's in public health from Saint Louis University School of Public Health. He has been on the faculty of Southern Illinois University-Edwardsville, St. Louis University, and St.Louis University School of Medicine. He is currently Associate Professor of Psychology at Lake Superior State University in Sault Sainte Marie, Michigan.

Barbara K. Searight received her Bachelor of Science degree in Special Education from Wayne State University, a master's degree in counselor education from St. Louis University and her Ph.D. in Public Policy and Administration from St. Louis University. From 1995-2007, she was Executive Director of the St. Louis Office for Developmental Disabilities in St.Louis, Missouri. Currently, she is an adjunct professor at Lake Superior State Univeristy in Sault Sainte Marie, Michigan and Algoma University in Sault Sainte Marie, Ontario as well as Executive Director of Habitat for Humanity for Michigan's Eastern Upper Peninsula. 